\title{
A!
}

This is an electronic reprint of the original article.

This reprint may differ from the original in pagination and typographic detail.

Kautonen, Heli; Nieminen, Mika P.

\section{Critical Look at the User-Centered Design Competencies}

\section{Published in:}

Proceedings of the 9th Nordic Conference on Human-Computer Interaction

DOI:

$10.1145 / 2971485.2971506$

Published: 01/01/2016

Document Version

Peer reviewed version

Please cite the original version:

Kautonen, H., \& Nieminen, M. P. (2016). Critical Look at the User-Centered Design Competencies. In Proceedings of the 9th Nordic Conference on Human-Computer Interaction (pp. 20:1-20:10). [20] (NordiCHI '16). ACM. https://doi.org/10.1145/2971485.2971506

This material is protected by copyright and other intellectual property rights, and duplication or sale of all or part of any of the repository collections is not permitted, except that material may be duplicated by you for your research use or educational purposes in electronic or print form. You must obtain permission for any other use. Electronic or print copies may not be offered, whether for sale or otherwise to anyone who is not an authorised user. 


\section{User-Centered Design Competency Model in the Field}

\author{
Heli Kautonen \\ Aalto University, \\ the National Library of Finland \\ Helsinki, Finland \\ heli.kautonen@helsinki.fi
}

\author{
Mika P. Nieminen \\ Aalto University \\ Helsinki, Finland \\ mika.nieminen@aalto.fi
}

\begin{abstract}
Public sector services are going through an extensive digital reformation, which intends to improve the quality of these services. A user-centered design (UCD) approach and skills are required if citizens are involved in the public services' production. In this paper we present a study in which we utilized the UCD Competency Model. The data for the study was collected in interviews with key informants from three exemplary public digital service projects. We used Critical Discourse Analysis methodology to reveal interviewees' explicit opinions and underlying assumptions about different aspects of UCD and required competencies among stakeholder groups. Our results indicate that public servants have favorable ethos and willingness to invest on UCD. Still, there is a need to reconsider the citizens' role as genuine participants, and norms that guide public service production. The study served as validation of the UCD Competency model, proving it applicable in the field as a thoughtprovoking trigger of change.
\end{abstract}

\section{Author Keywords}

User-Centered Design Competency Model; field-testing; public services; digitalization; Critical Discourse Analysis.

\section{ACM Classification Keywords}

H.5.2 Information interfaces and presentation (e.g., HCI): User Interfaces, User-centered design. K.6.1 Management of computing and information systems: Project and People Management, Strategic information systems planning.

\section{INTRODUCTION}

Extensive digitalization of public sector services is expected to improve the efficiency of public service production as well as the quality of these services. The recent economic climate and major demographic changes increase the motivation for public sector digital reform [2]. In Europe, there are national initiatives aiming at ambitious e-government infrastructures $[3,4]$, and also the European Commission calls for

Paste the appropriate copyright/license statement here. ACM now supports three different publication options:

- ACM copyright: ACM holds the copyright on the work. This is the historical approach.

- License: The author(s) retain copyright, but ACM receives an exclusive publication license.

- Open Access: The author(s) wish to pay for the work to be open access. The additional fee must be paid to ACM.

This text field is large enough to hold the appropriate release statement assuming it is single-spaced in Times New Roman 8-point font. Please do not change or modify the size of this text box.

Each submission will be assigned a DOI string to be included here. information and communication technology (ICT) enabled public sector innovations in its member states [1].

Without adequate attention on citizens' role in public sector digitalization, the endeavor may produce more issues than it solves. Recently, there has been an increasing interest in the involvement of citizens in public service production as an additional resource [5], or as participants in policymaking [6, 7]. E-government innovations bring along new challenges. To meet citizens' heterogeneous needs, special design capacities and abilities are needed [8]. To include usability in the procurement of government systems requires other kinds of knowledge [9, 10]. Involving citizens in co-design activities turns the focus on yet other design abilities [11, 12] that are required from members of the design team. Altogether, it seems to us that there is a demand for a comprehensive understanding of user-oriented skills, abilities, knowledge and competencies that facilitate designing better services for citizens.

In this paper we address citizens' role in the public sector's digital service development by presenting a study, in which we explored the competencies of user-centered design in the field. Our aim was to seek design practitioners' skills, abilities and attitudes that could serve as good examples for forthcoming digitalization initiatives in the public sector.

As a promising instrument for user-centered design competency assessment, we introduce Nieminen's recent model of User-Centered Design Competencies [13]. We set some real design cases against the model, and examined the applicability of the model on the field. Thus, our study served as validation for Nieminen's model.

This study is grounded in sociological theories of practice and in the notion that all phenomena in our everyday lives, from the level of international politics to a single person's work tasks, are shaped and enabled by social structures and meaning-making [14].

This study is part of a wider research study that examines user-centered design strategies in public digital service production in one Scandinavian country. This wider study 


\section{User Strengths}

Subject Domain

Experience (SDE): (Tacit)

knowledge, crafts and skills

gained by (long) experience.

Context Availability (CA):

Access to real context of use, may be restricted or difficult to arrange.

\section{User Cultures, Social} Networks and Practices (USP): Each user groups have their own language and culture that can be difficult to grasp and utilize in a design project.
Soft Skills

Communication (C): Well-

functioning and democratic

communications are the most

time consuming and critical part of design work.

Multidisciplinarity and

Collaboration (MC):

Multiple points of view

increase the eventual impact of design.
Designer Strengths

User Involvement (UI):

Capabilities in selecting the

right users and working with

them effectively.

\section{Problem solving and}

Designerly ways (PSD):

Attitude and determination

towards designing a change

for the better and having the

means to realize it in a

responsible manner.

Motivation and Ambitions

(MA): Intrinsic motivation,

self-improvement,

professional ambitions,

competitive salary and

manageable workload create

solid design conditions.

\section{Conceptualization,}

Visualization and creating product concepts, prototyping and testing.
Validation (CVV): Skills in

\section{Hard Skills}

Process and Methods (PM):

Process, management and methodological excellence and the skills to adapt them.

\section{Technology and Market}

Potential (TMP): Awareness of advances in available technologies and relevant trends at target markets.

\section{Subject Domain}

Knowledge (SDK)

Knowledge and skills gained by education and certification.

Table 1. UCD Competency Model according to Nieminen, 2015

dictated our choices concerning the scope of this study, and selection of cases and actors.

\section{USER-CENTERED DESIGN COMPETENCIES AND DYNAMICS OF SOCIAL PRACTICES}

\section{Competency approach to User-Centered Design}

Throughout its history, User-Centered Design (UCD) has emphasized involvement of users and other stakeholders in the design process in all stages [15, 16], and UCD emphasizes the need for multidisciplinary design teams [17]. The design of interactive products and services requires deeply specialized skills and knowledge from various fields or domains, and it is essential for these multiple disciplines to have effective methods for collaborating with each other. This is where competencies and competency models come in to the picture. Competency models offer a way to structure and measure the "knowledge, skill or ability, personal characteristic or a cluster of two or more of these attributes" necessary for effective performance [18]. In the past, competency models have often been limited to performance management, facilitating dialog on human resources' issues [19], or improving recruitment and employee selection practices [20]. However, past competency models also provide valuable tools for multidisciplinary UCD projects by identifying and clarifying the required skills, knowledge and characteristics [21], which ultimately contribute to improving both individual job performance and organizational effectiveness [22].

Some competency models cover parts of UCD (such as the Skills Framework for the Information Age [23] or the Software Engineering Competency Model [24]), but they do not sufficiently focus on the operational team level design practices that are interesting and relevant in user-centric design of digital services. This is why we chose a recently published UCD Competency Model by Nieminen [13] as a baseline for our study. This model is outlined in Table 1.

\section{UCD Competency Model}

The UCD Competency Model [13] covers the 12 most essential competencies for User-Centered Design. The model structures the competencies into four categories: User Strengths or Designer Strengths based on the role of the participant and Soft Skills and Hard Skills based on the innate or learned nature of the competency (e.g., skills and knowledge). The UCD Competency Model provides a short description and it defines three levels of expertise on a 5point scale for each competency.

UCD Competency Model was validated through a questionnaire study where practicing designers were asked to apply the model to one of their recent projects. They used a provided spreadsheet as a self-assessment tool to analyze their team members' and users' competencies and also to provide feedback about the model. The original validation confirmed that the model does include the most relevant aspects of UCD, that it was found statistically reliable and valid and that it was capable to reliably distribute participants to different competency levels. [13]

Main challenges for applying the UCD Competency Model to real life projects were that the model was found quite time consuming. Time required to apply the model to a single project varied from 40 minutes to 4 hours. Also assessing some of the competencies from the point of view of all the stakeholders was sometimes found difficult. For instance, the 
designers found it difficult to reliably rate the end users' communication skills. [13]

\section{Social Practices, Meaning and User-Centered Design}

Social theories of practice give explanation to our everyday activities and their change. When empirical work activities are studied through these theories, focus can be aimed at, for example, human factors and their influence on different functions of the work [25]. In this study we examined design practitioners' skills, abilities, and attitudes that make them do what they do. Therefore we adopted our viewpoint to design work practices from Shove and Pantzar [14], who construct their social practice theory form three elements: materials, competences, and meaning. According to Shove and Pantzar, emergence of new social practices requires active dynamic links between these three elements.

Many practices in our society emerge from the evolution of new material elements such as tools and technology [26]. Quite naturally, there must also be people skilled and knowledgeable enough to use appropriate tools and technology. Shove and Pantzar [14] argue that, in order to truly emerge as an established social practice, the activity must have a meaning to people in the given context. Only then can people engage themselves with this new activity.

The Figure 1 illustrates the three elements of UCD: material, competence and meaning. In addition to testing the second element (competence in UCD) we explore the third (meaning of UCD) in the context of public digital service development.

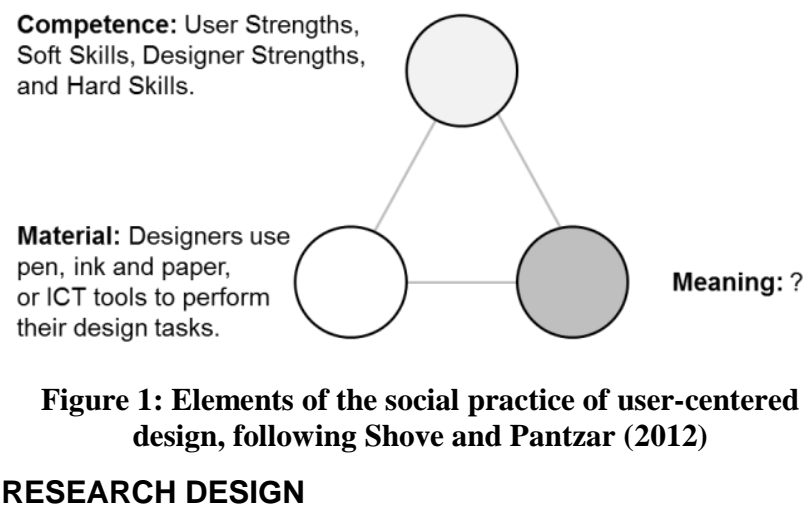

\section{Scope of Research and Research Questions}

The purpose of our study was to explore citizens' roles in public service production by studying competencies of usercentered design in the field within the scope of public service digitalization. Because of the link to a wider research study, we focused on public services that preserve and provide access to cultural heritage in one Scandinavian country. Through the primary author's long work experience in the public sector and her personal contacts, we were able to classify ongoing digital service projects regarding their approach to UCD.

Positive design ideologists criticize the problem-based focus and decision paradigms, which, in their opinion, rule our current design processes, particularly in the field of ICT [27,
28]. The positive design approach implies that untamed realworld problems can be solved by building upon existing positive examples rather than examining problematic issues [27]. Taking this viewpoint, we decided to seek projects that give a positive example of the UCD approach. In other words, we wished to learn what works in terms of UCD competency, instead of finding deficiencies in that area. There is already evidence in the literature about public sector ICT projects that lack user-perspective [see, e.g., 29].

In our opinion, there are enough good examples with supporting evidence about UCD methods can be used and what kind of professional expertise should be involved in service development. Since the symbolic significance (the meaning associated with UCD) may affect the direction to which this social practice evolves [14], we wished to turn our attention on that aspect of design practice.

From this contemplation we composed our first research question: What constitutes exemplary UCD Competencies and attitudes for building digital services in the public sector? We also wanted to know, if there were still some deficiencies in team members' competencies, hindering an optimal user-centered approach.

One of our study aims was to validate Nieminen's UCD Competency Model [13] in the field. We wanted to examine some issues that were unaddressed in the previous study. Specifically, we wished to set the model against everyday activities and observe UCD practitioners' response to it.

Therefore, our second research question was: How does the UCD Competency Model integrate with the practice of developing public digital services?

When combined, answers to these questions should illuminate practitioners' perceptions of UCD Competencies in the public sector.

Research Methodology: Critical Discourse Analysis

Work-related human activities can be seen as social practices that have their own characteristics and dynamics [14]. Thus, UCD as part of ICT development work can be analyzed as a social practice by using the conceptual instruments provided by sociological theories.

Different variations of discourse analysis provide theoretical framework and methodology for analyzing social practices and their constitution in and from discourses [30]. At the core of discourse analysis theories is the thesis that social and cultural processes are discursive. This means that processes of text production and consumption can reveal the characteristics of related social practices [30-32].

Discourse analysis has been recognized as a legitimate methodology for the research of societal power relations, especially in transdisciplinary studies of media, political and organizational discourses [32, 33]. Despite its apparent suitability to studies of human perceptions, there seems to be only a few studies that utilize discourse analysis in the context of Human-Computer Interaction (HCI). Recently, 
more interesting studies advocating the importance of discourses for revealing problematic HCI design issues have emerged [34-36]

Despite the fact that there is scarcely supportive evidence, we believe that discourse analysis can serve as an effective method for examining the perceived competencies in the context of digital service development. By analyzing professionals' language use we can also reveal their discursive practices and how they identify their own and other team members' skills and abilities in their speech.

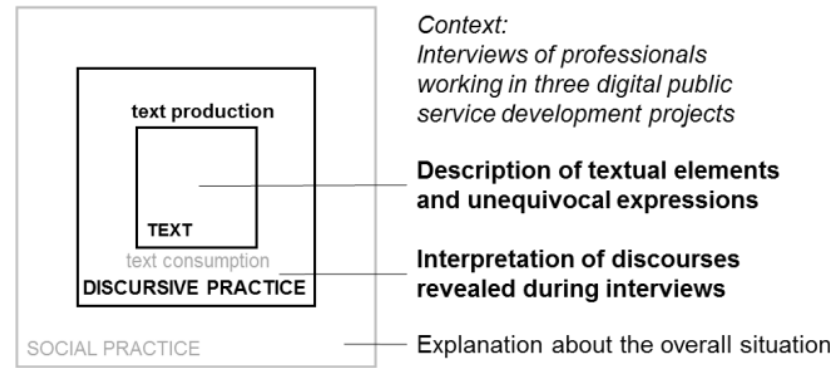

Figure 2: Levels of analysis in this study, mapped on Fairclough's (1995) three-dimensional model of Critical Discourse Analysis

Of the various approaches to discourse analysis, we chose the Faircloughian Critical Discourse Analysis (CDA), because it seemed most appropriate for revealing spoken and unspoken opinions and practices. Critical Discourse Analysis aims to illuminate unrealized problems, possibilities and taken-for-granted ideologies [30-32]. CDA pays attention to the language, the discourses revealed from the use of language, and social practices that are constituted by and from the discourses [30]. The analysis of discourses cannot detect all variables of cultural activity, but it can indicate existing practices related to certain discourses [31, 32].

Fairchlough's model for critical discourse analysis has three dimensions: text, discursive practice, and social practice (see
Figure 2). In this study we were able to apply only the first level (text) in full extent, and the second level (discursive practice) partially. Researchers rarely have access to real life settings where discourses occur [30]. Still, it is considered acceptable and useful to conduct the analysis on available levels, since this analysis may reveal some aspects that indicate relevant discursive practices, or social practices.

\section{Data Collection: Three Cases from the Field}

We obtained the data for this study from three public digital service projects. We chose these projects from among ongoing public ICT projects in the country, because they were known to represent exceptional approaches to users' needs. Each of these projects had hired or acquired personnel solely for user interaction design. According to literature, managerial strategies that allow resources in UCD are not overly common in the public sector [37]. Overview of projects can be seen in Table 2 .

The first project (A) aims at developing an online service for acquiring material from various cultural heritage repositories. The system is developed within a public institution, and there is also a team of interaction designers in the unit responsible for the service. The first version of the interface was published in 2013, but the project is still operational, and the service has not yet reached its maturity.

The second project (B) aims at developing a national online service that integrates information from several back-end repositories, and integrates various government and other public services to the same interface. The outcome of the project was launched some months after the interviews. The team responsible for building the system consisted of inhouse developers in a government office and outsourced experts. Design activities involving user needs and user interfaces was outsourced to a small/medium enterprise specialized in service design.

The third project (C) differed from the previous two in its scale and aims. It is a typical public acquisition of ICT

\begin{tabular}{l|l|c|c|c} 
Project & \multicolumn{1}{|c|}{ Purpose of the service / target group } & $\begin{array}{c}\text { UCD Designers' } \\
\text { Status / personnel } \\
\text { per year }\end{array}$ & $\begin{array}{c}\text { Interviewee's role } \\
\text { in the project }\end{array}$ & Analysis units \\
\hline Pilot & (Project B) & (Project B) & 3 Interaction Designers & P5 \\
\hline Project A & $\begin{array}{l}\text { National e-government service / citizens in } \\
\text { a nation }\end{array}$ & Outsourced / 2-5 & $\begin{array}{c}\text { Content Manager } \\
\text { Project Manager }\end{array}$ & $\begin{array}{c}\text { P1, P2 } \\
\text { P7 }\end{array}$ \\
\hline Project B & $\begin{array}{l}\text { National discovery service for materials of } \\
\text { science and culture / citizens in a nation }\end{array}$ & In-house / 1-3 & $\begin{array}{c}\text { Intervaction Designer } \\
\text { Projer }\end{array}$ & P3 \\
\hline Project C & $\begin{array}{l}\text { Digital library / citizens with reading } \\
\text { disabilities in a nation }\end{array}$ & Outsourced / <1 & $\begin{array}{c}\text { Interface Designer } \\
\text { Project Manager }\end{array}$ & P9, P10 \\
\hline Pilot test $+\mathbf{3}$ projects & & Interface Designer & P6 \\
\hline
\end{tabular}

Table 2. Overview of analyzed projects and research material 
system's development. Also the interface design expertise was outsourced to a small enterprise that specialized in interface design. The interviews were conducted at the moment of launching the project. In fact, some of the people involved in the development had not yet seen each other but knew of each other by reputation.

The primary author is familiar with these projects through her work, and was able to access public and internal documents describing these projects and their plans. However, the documents did not reveal detailed enough information concerning UCD or knowledge, skills and abilities in relation to design considerations. Therefore, we decided to interview key people from each project and utilize the UCD Competency Model in these interviews.

Because of the primary author's long work experience in the field, we were able to recruit informants who represented the best insight into UCD within each project. We interviewed the Project Manager responsible for work organization and goal setting for each project. We also interviewed lead designers who were responsible for interaction or user interface design of each outcome. In Project A, we also interviewed the Content Manager, who was involved in the concept and interaction design of the service.

As a pilot test, we introduced the UCD Competency Model and the questionnaire exactly the way Nieminen [13] had presented it: We sent the introduction and the form to three test subjects from Project B and asked them to fill in the form. We validated their answers in a group interview and we paid special attention to their comments about the usage of the model. Surprisingly, they all considered the form extremely frustrating and expressed strong reluctance about the use of numbered scales on the form. Since they still appreciated the approach and the model itself, we decided to continue interviews without the form. After the pilot test, we used the model as an open structure for interviews, and operationalized relevant concepts afterwards. The pilot test group interview was included in the research material, since it contained equally genuine perceptions about the model and competencies as further interviews.

In each interview, we asked some preliminary questions for getting an understanding of project goals and interviewees' roles in the projects. Then we moved on to the model. We asked complementary questions throughout the interviews when necessary.

First, we asked each informant to identify the most important stakeholder groups from the viewpoint of the project and its outcome. In addition to groups presented in the model (End Users, UCD Designers, Developers), interviewees identified other groups or subgroups that were involved in design and development during the active project phases. These additional groups included service officials (Projects A, B, C), partner organizations (Projects A and B), government offices (Project A), and strategic level stakeholders or decision makers in the ministry (Project A).
All interviews included a walkthrough of the UCD Competency Model (see Table 1). We asked interviewees to roughly describe their understanding of the level of each competency among different stakeholder groups. We reminded them of other groups, if they seemed to answer only on behalf of the most apparent group responsible for a competency. Finally, we asked interviewees' opinion of the model.

Altogether, we interviewed eight people, two of them were interviewed in two sessions. Altogether, there were 11 interviews resulting in 12 hours of recorded material. The recordings were transcribed into 11 documents (130 total pages) for further elaboration.

\section{Validity and Reliability}

Qualitative research entails inductive and interpretative elements, and therefore validation instruments for each study must be in conformance with chosen theoretical frameworks and methodologies [38]. We paid attention to validity and reliability issues by following suggested protocols of CDA [30], and maintaining coherence throughout the process.

We viewed the data through multiple theoretical viewpoints to ensure construct validity. This technique can reveal meaningful aspects of the phenomenon as well as other, more typical forms of triangulation [38]. The primary author was in charge of conducting interviews and transcript coding. Therefore, to ensure internal validity of the findings, the other author checked the codes and constructs and evaluated interpretation of discourses.

\section{DATA ANALYSIS}

Operationalization of unstructured qualitative material requires a systematic approach and tools for data management [38]. We used Atlas.ti software for coding identified conceptual constructs from interview transcriptions, and for pattern recognition. In addition, we used normal office software for representation purposes. We did not conduct any statistical analyses, because the data set was relatively small and we did not consider comprehensive data quantification meaningful for the purpose of the study.

\section{Two Levels}

Following the Faircloughian Critical Discourse Analysis methodology [30-32, 39], we analyzed the material on two levels: the textual level and the discourse level. In practice this meant that we coded the material in several iterations: first we looked for expressions on the textual level and then on the discursive level.

The textual level analysis reveals explicit expressions and the obvious use of language. The aim is to operationalize natural language expressions into concepts (codes) that help identify of patterns or themes.

On the discourse level, the aim of analysis is to detect patterns of articulation, and explicit or implicit expressions of power relation. Linguistic values may also serve as indicators of meaning. Therefore, the analyzer must look for 
linguistic clues (such as significant terms, use of verb tenses or exaggerations of detail) to find all relevant expressions.

The analysis of social practices, which is the ultimate level of analysis, requires access to a wider set of discourses in the given social context. However, findings from other levels may indicate potential social practices and their dynamics.

\section{Three Phases}

We analyzed the material in three phases that aimed at three distinct goals: 1) Identification of opinions about the model and its applicability to practice; 2) Identification of UCD competencies and differences within each project; and 3) Identification of underlying power relations and attitudes. Overview of these phases can be seen in Table 3.

The first phase served our aim to validate the UCD Competency Model in the field and test practitioners' responses about it. We looked for informants' explicit opinion statements about the UCD Competency model and we processed those using descriptive codes. In this phase, we traced concepts of Nieminen's model and interviewees' positive or negative assessments of the model and its aspects.

Also, the second phase served our aim to validate the model, but in this phase we looked for interviewees' perception of their project stakeholders' skills and competencies. From their assessment results, we could conclude if the model served in real world situations.

Because we abandoned the questionnaire form, we asked interviewees to use distinctive statements when describing their team members' or project stakeholders' skills and abilities. During the analysis, we first coded the interviewer's questions and respective answers following the UCD Competency Model. In order to distinguish assessments given in natural language, we then looked at interviewees' expressions through the lens of the status characteristics theory by Berger et al. [40]. We processed the material identifying dual characteristics as high status or low status, when such intention could be interpreted from the text.

The last phase served most our primary aim to explore digital service developers' perceptions of UCD Competencies in the public sector. This phase required synthetization codes and findings from previous phases, as well as new coding and interpretations.

In the third phase we needed auxiliary instruments for operationalizing interviewees' discourses and ideologies. When browsing through the material, we detected expressions that indicated some type of value in relation to user-centered design. We coded them using two of Graeber's [41] types of values: sociological and economic. In addition, informants referred occasionally to external norms, such as WCAG-guidelines. These references were coded as normative value expressions, following Bicchieri's [42] viewpoints.

\section{RESULTS}

First Phase: Opinions of the UCD Competency Model

The textual level analysis provided findings concerning interviewees' opinions of the UCD Competency Model.

In response to aggressive objections about the use of the evaluation form, we abandoned it and used the model as a basic structure for the interviews. This decision was supported by our findings from actual interviews, since interviewees, particularly from Projects $\mathrm{B}$ and $\mathrm{C}$, emphasized the importance of discussion with interviewer (6 occurrences), interpretation of options with the interviewer (6 occurrences), or the interviewer's help regarding the different aspects of the model (8 occurrences).

Interviewees found the identification of relevant stakeholder groups very useful and considered using that method in their future projects. They mentioned that assessment of competencies between these groups was difficult. They considered skills more typical for a single person than for a group (7 occurrences). Also, assessment of end users' skills against the model seemed more difficult than for other groups.

After the pilot test, interviewees expressed more positive than negative statements about the model. Some informants appreciated the model because it provoked thoughts towards

\begin{tabular}{|c|c|c|c|}
\hline Phase & Goal of analysis & Constructs for coding & $\begin{array}{l}\text { Conceptual } \\
\text { framework }\end{array}$ \\
\hline 1 & $\begin{array}{l}\text { Identification of opinions of the } \\
\text { model and its applicability to practice }\end{array}$ & $\begin{array}{l}\text { Expressions of assessment: positive / negative } \\
\text { Aspects of model under interviewee's judgement }\end{array}$ & Nieminen, 2015 \\
\hline 2 & $\begin{array}{l}\text { Identification of UCD competencies } \\
\text { and differences within each project }\end{array}$ & $\begin{array}{l}\text { UCD Competency Model question-answer dyads } \\
\text { Expressions of status: high / low }\end{array}$ & $\begin{array}{l}\text { Nieminen, } 2015 \\
\text { Berger et al., } 1972\end{array}$ \\
\hline 3 & $\begin{array}{l}\text { Identification of underlying } \\
\text { power relations and attitudes }\end{array}$ & $\begin{array}{c}\text { Expressions of value: sociological / economic } \\
\text { Expressions of value: normative }\end{array}$ & $\begin{array}{l}\text { Graeber, } 2010 \\
\text { Bicchieri, } 2006\end{array}$ \\
\hline
\end{tabular}

Table 3: Aligning phases of analysis with different conceptual frameworks 
different aspects of design, others anticipated using a similar kind of reflective assessment in their future projects.

\section{Second Phase: Assessment of Project Stakeholders' Competencies}

Our findings from the second phase were based on both textual and discursive level analyses. In the next chapters, we indicate detected differences in skills and the perceived higher or lower status of each group in relation to others.

User Strengths: Interviewees considered end users most experienced in their own subject domain (SDE), context (CA), cultures and practices (USP), but interviewees also mentioned that users may not be aware of these in a usable way. Furthermore, interviewees thought that users know only their own spheres, and are often not aware or interested in other users' needs.

Designers in Projects A and B were considered more skilled in User Strengths than the users themselves, partly because they were seen as target group members (i.e., citizens) themselves. Thus, designers were perceived to have the highest status in User Strengths.

In Project A, there was also a notion that among other interest groups there are government offices and entities whose User Strengths can vary from extremely poor to exceptionally good, depending on their motivation and awareness about user-centered design.

Soft Skills: Only 3 interviewees out of 8 gave any comments about end users' communication (C) and collaboration skills (MC). Others commented that these competencies were not relevant for end users at all.

None of the groups was considered to have a particularly high or low status in regard to Communication, Multidisciplinarity, or Collaboration. However, all stakeholder groups, including end users, were considered highly motivated and ambitious in relation to these projects and their outcomes.

Designer Strengths: Interviewees considered this set of skiFulls most irrelevant in relation to end users' competencies. One of them expressed that although one would involve users in co-design activities, end users are not expected to possess these skills.

Designers' and developers' skills in this aspect were considered the same or higher than average, but quite naturally, designers were given a considerably higher status than developers in their Designer Strengths.

Interviewees pointed out that particularly the groups that represented the customer service were very essential partners for designers since they knew best their end users' language so they could provide irreplaceable help during the concept design phase. Thus, the status of these customer representatives was considered high.

Hard Skills: Again, Project Management in regard to end users caused complaints, since managerial tasks were not considered relevant from the end users' perspective. However, for Projects A and B end users' technology and market potential (TMP) skills were estimated high: target users expect high quality and modern public services. Project $\mathrm{C}$ also indicated such expectations, but noted that there may occur some resistance to change among their less technically oriented end users.

Quite expectedly, the technology and market potential (TMP) skills were considered very high among developers. The interviewees from Project A considered surprisingly good knowledge of technological trends in the group of government decision makers. Altogether, developers' status was considered the highest in Hard Skills.

The last and most interesting comment came in regard to subject domain knowledge (SDK). An interviewee from Project A emphasized that there is no such thing as citizen education. He said that it is actually the objective of a userfriendly government service to reduce the need for such.

\section{Third Phase: Discourses of UCD Attitudes}

The third phase of our study examined professional discourses about experienced power structures and values, which was interpreted from interviewees' expressions of their project in relation to their goals, different stakeholder groups, and society. Elaboration of the discourses from relevant codes can be seen in Table 4 .

From all detected discourses we selected six most relevant.

- Discourse of public servant ethos towards UCD. In each project, user involvement was considered an essential element for getting better results. However, we understood that some of the interviewees did not speak of the produced service's actual end users but of internal users. Still, a very strong public servant ethos was apparent in interviewees' comments, particularly when they were speaking about their motivation to develop these public services with usercentered approaches.

"We bring an altruistic public servant ethos to this." (P1)

- Discourse of patronization over end users. All interviewees indicated strong faith in the power of design, and development teams' ability to design a good service for their end users. Designers in Project C expressed strong professional user-centered design ethos. Although each project was proudly presented as user-centric, users had not been or were not intended to be involved in design activities other than user testing. One interviewee doubted end users abilities to express their needs, and others considered that it is the design team's responsibility to aid users. Overall, we interpreted an underlying patronizing sentiment that users are not capable of acting for themselves, or understanding the restrictions of public service production.

“...and customers would have brainstormed all kinds of widgets..." (P6) 


\begin{tabular}{|c|c|c|c|}
\hline Power relation & Relevant codes & Appearance in project/s & Interpreted discourse \\
\hline $\begin{array}{l}\text { End Users - Professionals in } \\
\text { the Project (incl. designers) }\end{array}$ & $\begin{array}{l}\text { user-involvement-important } \\
\text { end-user-emancipation } \\
\text { public-servant-ethos }\end{array}$ & $\begin{array}{l}\text { A, B, C } \\
\text { B } \\
\text { A, C }\end{array}$ & $\begin{array}{l}\text { Public servant ethos towards } \\
\text { UCD }\end{array}$ \\
\hline $\begin{array}{l}\text { End Users - Professionals in } \\
\text { the Project (incl. designers) }\end{array}$ & $\begin{array}{l}\text { users-need-professionals'-help } \\
\text { UCD-ethos }\end{array}$ & $\begin{array}{l}\mathrm{A}, \mathrm{B}, \mathrm{C} \\
\mathrm{C}\end{array}$ & Patronization over end users \\
\hline Designers - Developers & $\begin{array}{l}\text { power-game } \\
\text { limited-resources }\end{array}$ & $\begin{array}{l}\mathrm{A}, \mathrm{B}, \mathrm{C} \\
\mathrm{A}\end{array}$ & $\begin{array}{l}\text { Power game between design } \\
\& \text { technology }\end{array}$ \\
\hline $\begin{array}{l}\text { Designers - Strategic level / } \\
\text { society }\end{array}$ & $\begin{array}{l}\text { normative-barriers } \\
\text { supportive-norms }\end{array}$ & $\begin{array}{l}\mathrm{A}, \mathrm{C} \\
\mathrm{C}\end{array}$ & Norms frame UCD \\
\hline $\begin{array}{l}\text { UCD in the Project - Other } \\
\text { roles in the Project }\end{array}$ & $\begin{array}{l}\text { organization-centric } \\
\text { catalyst-of-change }\end{array}$ & $\begin{array}{l}\mathrm{A}, \mathrm{B}, \mathrm{C} \\
\mathrm{A}, \mathrm{B}, \mathrm{C}\end{array}$ & $\begin{array}{l}\text { UCD serving as a catalyst of } \\
\text { change }\end{array}$ \\
\hline $\begin{array}{l}\text { UCD in the Project - } \\
\text { Strategic level / society }\end{array}$ & $\begin{array}{l}\text { willingness-to-invest } \\
\text { ideal-vs-practice } \\
\text { nobody's-interest }\end{array}$ & $\begin{array}{l}\text { A, B, C } \\
\text { A, C } \\
\text { A }\end{array}$ & $\begin{array}{llr}\text { More good will than } \\
\text { understanding } \\
\text { requirements }\end{array}$ \\
\hline
\end{tabular}

Table 4: Aligning aspects of analysis with detected discourses

- Discourse of power game between design \& technology. Each project seemed to require close co-operation between designer and technical developers. On many occasions, the designers' mentioned the professional tension between designers' demanding design goals and developers' restricted technical approach. Also other project members addressed the power game between these professional groups, but stated their input and expertise were equally important for the outcome. Still, in each project the UCD designers were given the lead for development activities, at least to some extent.

"[Technical developers are] always pulling to another direction." (P8)

- Discourse of norms framing UCD. Altogether, interviewees' made several references to external norms that either support or restrict design intentions. None of the norms were mentioned by more than one interviewee, but it seems that each of these norms have considerable meaning to some aspect of UCD competency in the team. For example, one informant mentioned that getting to know WCAG guidelines has improved his designer skills.

"Legislation puts it to a halt." (P1)

- Discourse of UCD serving as a catalyst of change. Interviewees implicated several areas where the usercentered approach or use of certain design methodologies had triggered fundamental change, not only in the scope of the project, but also in wider public service practices.
Some of them considered this change as the primary goal of the entire project. We interpreted that there was a discourse indicating the user-centered design approach as a (desired or opposed) catalyst of change.

"Our role is to challenge their mental model." (P8)

- Discourse of more good will than understanding of UCD requirements. In each project, interviewees expressed their gratitude that their decision makers were willing to invest on UCD design. Such ICT policy was considered exceptional, although it is increasing. The Manager in Project A praised the recent governmental mandate to invest resources in UCD, although he also emphasized that the decision makers have more good will than understanding of the requirements in practice. Also representatives from Projects B and C expressed that ideals are far from getting UCD work into practice.

"[in the public sector, in relation to UCD] there is no top class knowledge in a way." (P11)

\section{DISCUSSION AND CONCLUSIONS}

Digitalization and innovation in the public sector requires open strategies and citizen-centric attitudes from public sector organizations [8]. This study provides practical insights into how these challenges have been faced in three exemplary projects that build public digital services in one Scandinavian country. Although these insights illuminate only a fraction of the field, we believe that the conclusions 
are transferrable to other projects and to the wider discussion about citizens' role in public service production.

We found that there is a strong public servant ethos among team members, who are involved in building new digital services for citizens. All involved stakeholder groups seemed highly motivated in their work, and interviewees anticipated that also their end users are highly motivated. This perception may be explained by the innovative nature of the projects under investigation. Nevertheless, such public servant ethos may generate appreciation towards usercentered design (UCD) in general, and improve the status positioning and identity of UCD designers within the development team. In organizations, high status is understood as an indicator of quality [43], which in turn accelerates appreciated members' performance and task competence [44]. Respect of UCD designers may thus create a positive loop that improves the outcome.

Our results revealed that people working in investigated projects appreciated decision makers' willingness to invest on UCD expertise. At the same time, they doubted that practical requirements of UCD activities are fully understood. This is in conformance with the notion that attention paid to user experience in public sector institutions varies widely [37]. Our result indicate that there is also a variety of norms that public service developers must follow. It may require exemplary talent to balance innovative design intentions among norms that do not acknowledge the citizens' active role.

When we looked for possible deficiencies in team members' competencies, our attention was drawn to the finding that end users seem to be considered less competent in many aspects. This kind of patronizing attitude has been recognized in the literature in other user participation settings [35]. It is argued that group members' perception of their intragroup status and respect influence their identity commitment and interaction towards the goal [45]. If end users are considered less competent from the beginning, their contribution to the outcome may not be utilized to the full extent.

In line with accepted discourse analysis practice, we studied only one side of the social interaction, the production of text in the context of an interview. Thus, we did not take into account discourses in natural social settings or other stakeholders' except designers', content and project managers' viewpoint. Furthermore, the study stemmed from just one country and its sample size was relatively small. These limitations provide directions for future research.

Our study implies that the UCD Competency Model may very well be integrated into the practice of developing public digital services. Interviewees' opinions support Nieminen's findings [13] that the application of the model may be challenging. Nevertheless, designers perceived the model as thought-provoking. While design requires consideration of possible futures [26], building excellent design teams requires understanding of desired competencies as well as possible stakeholders. In such considerations, the UCD Competency model can serve as a catalyst of change, by provoking new ideas.

\section{ACKNOWLEDGMENTS}

We owe our gratitude to the interviewees from (excluded for the anonymity of review) who gave their valuable time and shared their thoughts to enable this study. We wish to thank the (excluded for the anonymity of review) for the financial support for this study.

\section{REFERENCES}

[1] Europe 2020 Flagship Initiative. European

Commission, Brussels, 2010.

[2] Daglio, M., Gerson, D. and Kitchen, H. Building

Organisational Capacity for Public Sector Innovation.

Background Paper In Proceedings of the OECD Conference

"Innovating the Public Sector: from Ideas to Impact"

(Paris, France, 2014), [insert City of Publication],[insert

2014 of Publication].

[3] eGovernment Strategy 2011-2015. The Danish Agency for Digitisation, City, 2011.

[4] Policy paper. Spending Review and Autumn Statement 2015: documents. HM Treasury and The Rt Hon George Osborne MP City, 2015.

[5] Collm, A. and Schedler, K. Strategies for Introducing Organizational Innovation to Public Service Organizations. Public Management Review, 16, 1 (2013), 140-161. [6] McMullin, J. Design for Policymaking. Elsevier Science, City, 2012.

[7] Koch, G., Rapp, M. and Kröger, N. Harnessing the Innovation Potential of Citizens: How Open Innovation Can be Used to Co-develop Political Strategies. Springer, City, 2013.

[8] Meijer, A. E-governance innovation: Barriers and strategies. Government Information Quarterly, 32, 2 (2015), 198-206.

[9] Jokela, T. and Buie, E. Getting UX Into the Contract. Elsevier Science, City, 2012.

[10] Knutsson, H. and Thomasson, A. Innovation in the Public Procurement Process. A study of the creation of innovation-friendly public procurement. Public

Management Review, 16, 2 (2013), 242-255.

[11] Trischler, J. and Scott, D. R. Designing Public Services: The usefulness of three service design methods for identifying user experiences. Public Management Review (2015), 1-22.

[12] Voorberg, W. H., Bekkers, V. J. J. M. and Tummers, L. G. A Systematic Review of Co-Creation and CoProduction: Embarking on the social innovation journey. Public Management Review, 17, 9 (2014), 1-25.

[13] Nieminen, M. P. User-Centered Design Competencies. Doctoral dissertatiion, Aalto University, Helsinki, 2015.

[14] Shove, E., Pantzar, M. and Watson, M. The Dynamics of Social Practice. Everyday Life and How it Changes. SAGE Publications, London, UK, 2012. 
[15] Gould, J. D. and Lewis, C. Designing for usability: key principles and what designers think. Communications of the ACM, 28, 3 (1985), 300-311.

[16] Gulliksen, J., Göransson, B., Boivie, I., Blomkvist, S., Persson, J. and Cajander, A. Key principles for user-centred systems design. Behaviour \& Information Technology, 22, 6 (2003/11// 2003), 397-409.

[17] Standardization, I. S. O. I. O. f. ISO 9241-210

Ergonomics of human-system interaction -- Part 210:

Human-centred design for interactive systems (2010 2010).

[18] Marrelli, A. F., Tondora, J. and Hoge, M. A. Strategies for Developing Competency Models. Administration and

Policy in Mental Health and Mental Health Services Research, 32, 5 (2005 2005), 533-561.

[19] Sparrow, P. Organizational competencies: a valid approach for the future? International Journal of Selection and Assessment, 3, 3 (1995 1995), 168-177.

[20] Cook, M. Personnel selection: adding value through people. John Wiley \& Sons, Chichester, West Sussex, England, 2004.

[21] Lucia, A. D. and Lepsinger, R. The art and science of competency models. Jossey-Bass, San Francisco, CA, USA, 1999.

[22] Markus, L., Thomas, H. C. and Allpress, K.

Confounded by competencies? An evaluation of the evolution and use of competency models. New Zealand Journal of Psychology, 34, 2 (2005 2005), 117-126. [23] Foundation, S. Skills Framework for the Informatin Age: SFIA 5 framework reference. London, UK, 2011. [24] Ardis, M., Fairley, D., Hilburn, T., Nidiffer, K., Towhidnejad, M., Willshire, M. J. and Guillemette, K. The Software Engineering Competency Model (SWECOM). public review draft, IEEE Computer Society, Los Alamitos, CA, USA, 2014.

[25] Norros, L., Savioja, L. and Koskinen, H. Core-Task Design: A Practice-Theory Approach to Human Factors. Morgan \& Claypool Publishers, City, 2015.

[26] Krippendorff, K. The Semantic Turn. A New Foundation for Design. Taylor \& Francis, Boca Raton, FL, USA, 2006.

[27] Faust, J. Positive Design. Journal of American Society for Information Science and Technology, 60, 9 (2009), 1887-1894.

[28] Avital, M. and Boland, R. J. Managing as designing with a positive lens. City, 2015.

[29] Kaipio, J. Usability in healthcare : overcoming the mismatch between information systems and clinical work. Aalto University, 2011.

[30] Jörgensen, M. and Phillips, L. J. Discourse Analysis as Theory and Method. SAGE Publications Ltd, City, 2002.

[31] Fairclough, N. Critical discourse analysis: the critical study of language. Longman, London, UK, 1995.

[32] Fairclough, N. Critical discourse analysis as a method in social scientific research. Sage, City, 2001.

[33] Bonnafous, S. and Temmar, M. Discourse Analysis and Human and Social Sciences. Peter Lang, Bern, Switzerland, 2013.
[34] Iivari, N. Discursive construction of 'user innovations' in the open source software development context.

Information and Organization, 20, 2 (2010), 111-132. [35] Iivari, N., Kinnula, M. and Kuure, L. With best intentions. A Foucauldian examination on children's genuine participation in ICT design. Information Technology \& People, 28, 2 (2015), 246-280.

[36] Vines, J., Pritchard, G., Wright, P., Olivier, P. and Brittain, K. An Age-Old Problem: Examining the Discourses of Ageing in HCI and Strategies for Future Research. ACM Transactions of Computer-Human Interaction, 22, 1 (2015), 27.

[37] Buie, E. and Murray, D. Usability in Government Systems. Morgan Kaufmann, City, 2012.

[38] Patton, M. Q. Qualitative Evaluation and Research Methods. SAGE, Newbury Park, CA, USA, 1990.

[39] Wodak, R. and Meyer, M. Methods of Critical Discourse Analysis. SAGE, London, UK, 2001.

[40] Berger, J., Cohen, B. P. and Zelditch, M. Status Characteristics and Social Interaction. American

Sociological Review, 37, 3 (1972), 241-255.

[41] Graeber, D. Toward an Anthropological Theory of Value: The False Coin of Our Own Dreams. Palgrave, New York, USA, 2001.

[42] Bicchieri, C. The Grammar of Society. The Nature and Dynamics of Social Norms. Cambridge University Press, New York, USA, 2006.

[43] Sauder, M., Lynn, F. and Podolny, J. M. Status: Insights from Organizational Sociology. Annual Review of Sociology, 38 (2012), 267-283.

[44] Randel, A. E., Chay-Hoon, L. and Earley, P. C. It's Not Just About Differences: An Integration of Role Identity Theory and Status Characteristics Theory. Status and Groups, 7 (2015), 23-42.

[45] De Cremer, D. and Tyler, T. R. A Matter of Intragroup Status: The Importance of Respect for the Viability of Groups. Status and Groups, 7 (2015), 1-21. 